\title{
RESENHA: DESAFIOS DA HUMANIDADE NO SÉCULO XXI
}

\author{
BOOK REVIEW: HUMANITY'S CHALLENGES IN THE 21ST CENTURY \\ RESEÑA: LOS DESAFÍOS DE LA HUMANIDAD EN EL SIGLO XXI
}

NASCIMENTO, E. P. Um mundo de riscos e desafios: Conquistar a sustentabilidade, reinventar a democracia e eliminar a nova exclusão social. Brasília: Fundação Astrogildo Pereira, 2020. 214 p. ISBN 978-85-89216-82-1.

Gabriel Leuzinger Coutinho ${ }^{1}$

Universidade de Brasília - UnB

Elimar Nascimento é sociólogo, com doutorado pela Universidade René Descartes Paris V, e professor permanente dos programas de pós-graduação do Centro de Desenvolvimento Sustentável da Universidade de Brasília (CDS-UnB) e do Centro de Ciências do Ambiente e Sustentabilidade da Amazônia da Universidade Federal da Amazônia (CASA-UFAM). Foi professor de diversas universidades, incluindo a Universidade Mondlane de Maputo (Moçambique, 1977-1979), a Universidade Federal da Paraíba - UFPB (1979-1985), a Universidade Federal de Pernambuco - UFPE (1985-1987) e a UnB (1987-2015), além de chefe da assessoria especial do governo Cristovam Buarque, no Distrito Federal (1995-1998).

Ele é autor e organizador de diversos livros que tratam direta ou indiretamente da sustentabilidade, como Economia, Meio Ambiente e Comunicação (2005), As Novas Dimensões da Universidade: Interdisciplinaridade, Sustentabilidade e Inserção Social (2012), Enfrentando os Limites do Crescimento: Sustentabilidade, Decrescimento e Prosperidade (2012) e Turismo e Sustentabilidade: Verso e Reverso (2018). Um mundo de

\footnotetext{
${ }^{1}$ Engenheiro eletricista pela Universidade de Brasília (UnB), especialista em Gerenciamento de Projetos pela Fundação Getúlio Vargas (FGV) e mestre em Política e Gestão da Sustentabilidade pela Universidade de Brasília (UnB). Doutorando em Desenvolvimento Sustentável na Universidade de Brasília (UnB). Coordenador do Grupo de Pesquisa em Direito Ambiental e Desenvolvimento Sustentável do Centro Universitário de Brasília (UniCEUB). ORCID: https://orcid.org/0000-0003-0797-0432. Lattes: http://lattes.cnpq.br/0561746625525691. E-mail:leuzinger.gabriel@gmail.com.
} 
Riscos e Desafios: Conquistar a sustentabilidade, reinventar a democracia e eliminar a nova exclusão social (2020) é sua obra mais recente. É composta por trabalhos publicados por ele nas décadas de 1990, 2000 e 2010. Esses textos foram revisitados, revisados e atualizados para dar origem a cada um dos capítulos do livro.

Nesta obra, Nascimento defende a tese de que os principais riscos da humanidade no século XXI são: o desastre ambiental, as ameaças à democracia e a nova exclusão social. Ele busca equacionar corretamente cada um destes problemas e indicar possíveis soluções, de modo a contribuir para o debate sobre como evitá-los. O livro possui três partes, cada uma delas dedicada a um destes riscos, além de uma introdução e uma conclusão. Como pano de fundo, ele aborda questões transversais a estes riscos: a globalização (ou mundialização, como prefere o autor), a aceleração das inovações tecnológicas e a expansão do neoliberalismo.

A Parte I trata da crise ambiental ou, como consta do título do livro, da conquista da sustentabilidade. Para isso, apresenta as principais alternativas ao modelo de desenvolvimento vigente, baseado majoritariamente no crescimento econômico. Essa parte contém dois capítulos ( 1 e 2). O primeiro apresenta a sustentabilidade como um novo campo, conforme concepção de Bourdieu, com regras de ingresso e conflitos próprios. Os seus agentes compartilham uma crença comum: que a crise ambiental ameaça o patamar civilizatório alcançado pela humanidade. São apresentadas ainda as principais formas de enfrentamento a essa ameaça, dentre as quais estão o desenvolvimento sustentável e o decrescimento. E é justamente o decrescimento o tema do segundo capítulo, no qual Nascimento organiza e explica os principais conceitos deste movimento, bem como as limitações que fazem muitos não o considerarem uma alternativa realmente viável.

A segunda parte contém dois capítulos (3 e 4). Busca mostrar a importância de reinventar a democracia no século XXI. Segundo o autor, a democracia, em sua forma atual, já não é capaz de responder às demandas da sociedade e de enfrentar os novos desafios mundiais. O Capítulo 3 detalha quais são as ameaças à democracia, por exemplo, a crescente apatia política e o repúdio às autoridades, fenômenos que se observam em boa parte do mundo. Menciona ainda o deslocamento do processo decisório da esfera pública para a esfera privada e a incapacidade das democracias, até o momento, de enfrentar a crise ambiental. O Capítulo 4 complementa o anterior ao apresentar algumas das ações que podem ser tomadas para salvaguardar as democracias, em especial a brasileira. São elas: repensar e reformar as formas de representação e aumentar a eficiência do Estado, 
tanto por meio da redução do seu custo quanto pelo aumento da quantidade e da qualidade dos serviços entregues aos cidadãos.

A terceira e última parte do livro é também a maior. Conta com três capítulos $(5,6$ e 7), nos quais o autor busca explicar as relações entre a modernidade, a globalização (ou mundialização) e a nova exclusão social. O Capítulo 5 discute se a globalização e a exclusão social são ameaças à modernidade. Em sua argumentação, o autor aborda questões como a crise do Estado-nação, a globalização da cultura e a precarização do trabalho. O Capítulo 6 dá continuidade a essas questões, mostrando como a globalização, a terceira revolução científico-tecnológica e o neoliberalismo impactaram a sociedade moderna. Nascimento explica como estes três fenômenos estão levando ao fim da sociedade industrial, o que não significa o fim da indústria, mas sim a sua substituição pela sociedade da informação. Concomitantemente, estes fenômenos estão impulsionando outros processos, notadamente o crescimento da exclusão social. Finalmente, o Capítulo 7 aborda de maneira mais detalhada a nova exclusão social, mostrando como o atual modelo de desenvolvimento está criando um grupo social que é, ao mesmo tempo, desnecessário economicamente, incômodo politicamente e perigoso socialmente.

$\mathrm{Na}$ breve conclusão do livro, Nascimento faz a conexão entre os argumentos desenvolvidos nas três partes do livro. Ele trata pouco dos aspectos mundiais, preferindo focar em como os riscos da humanidade impactam o Brasil. O autor conclui que, ainda que os riscos da crise ambiental e da nova exclusão social sejam relevantes no país, o desafio imediato é o de proteger o regime democrático brasileiro, que, segundo ele, está sofrendo um ataque silencioso e gradual, mas corrosivo.

Livros como esse, que reúnem diversos trabalhos elaborados durante um longo período de tempo, muitas vezes têm dois problemas. Primeiro, os textos podem não conversar entre si, o que faz a obra ficar sem fluidez e coesão, dificultando a compreensão dos argumentos. O segundo problema é que alguns capítulos, por serem baseados em trabalhos muito antigos, podem estar desconectados do presente, ainda que o autor atualize os dados utilizados.

Nascimento lidou com esses problemas das seguintes formas. Com relação ao primeiro problema, o leitor notará que, em alguns momentos, não fica clara a relação entre os capítulos de uma mesma parte, problema que é atenuado, mas não anulado, pela introdução que o autor faz a cada uma das três partes. O importante é que isso não atrapalha o entendimento dos argumentos, pois a interligação das três partes entre si e com a tese mais ampla do autor é bem construída tanto na introdução quanto na conclusão da 
obra. Quanto ao segundo problema, ele não ocorre nesse livro. Até mesmo o capítulo baseado em um artigo escrito na década de 1990 se mostra atual e em sintonia com o presente, o que é verdade também para todos os demais capítulos.

Do ponto de vista do conteúdo, a obra dialoga com diversos autores e correntes de pensamento ligados à sustentabilidade, à economia e à sociologia. No campo da sustentabilidade, o autor segue principalmente a linha de autores ligados ao decrescimento, como Nicholas Georgescu-Roegen, Ivan Illich, e Herman Daly. Há também forte influência de Edgar Morin. Na interseção da sustentabilidade com a economia, Nascimento usa ideias de Amartya Sen e Ignacy Sachs, havendo referências também a Celso Furtado e Donella Meadows, para citar apenas algumas. Na sociologia, o autor conversa com vários pensadores da modernidade e da pós-modernidade: Jean-François Lyotard, Alain Touraine, Robert Castel, Anthony Giddens, Ulrich Beck, entre outros.

O texto entrega aquilo que promete no início: contribui para o debate sobre como evitar os principais riscos da atualidade. O que deve ficar claro, entretanto, é que a sua contribuição principal é caracterizar e detalhar esses riscos, bem como justificar porque são eles os principais desafios que o mundo enfrenta no momento. Não é, portanto, uma obra que proponha soluções inovadoras para esses problemas, o que o autor deixa claro desde o início. Por exemplo, ele apresenta como formas de alcançar a sustentabilidade o desenvolvimento sustentável e o decrescimento, duas ideias já consolidadas e, até certo ponto, antigas, embora não ultrapassadas. Trata-se de um livro que oferece ao leitor mais perguntas que respostas, o que não é, de forma alguma, um demérito. Como escreve Cristovam Buarque no prefácio, esta é uma obra para inspirar e não para ilustrar.

\section{REFERÊNCIAS}

NASCIMENTO, E. P. Um mundo de riscos e desafios: Conquistar a sustentabilidade, reinventar a democracia e eliminar a nova exclusão social. Brasília: Fundação Astrogildo Pereira, 2020. 214 p. ISBN 978-85-89216-82-1.

Resenha recebida em: 10 de novembro de 2020. Aceita para publicação em: 11 de novembro de 2020.

Book Review received on: November 10, 2020

Accepted for publication on: November 11, 2020 